\title{
Cerebral involvement in primary mixed cryoglobulinaemia
}

\author{
Amos Pines \\ M.D. \\ EHUD GOLDHAMMER \\ M.D.
}

NAOMI KaPLINSKY

M.D.

OTto FrankL

M.D. Department of Medicine F, The Sheba Medical Center (Affiliated to Tel-Aviv University Medical School).
52621 Tel-Hashomer, Israel

\begin{abstract}
Summary
Primary mixed cryoglobulinaemia was diagnosed in a 65-year-old woman and confirmed on post-mortem examination. The patient had the classical findings of purpura, arthralgia, renal failure, mixed cryoglobulins in the serum and rheumatoid factor activity. The patient presented with haemolytic anaemia and later developed rectal bleeding, but the most prominent feature was an acute psychosis with electroencephalographic changes, that was attributed to the disease and responded well to corticosteroids. Primary mixed cryoglobulinaemia should be included in the differential diagnosis of central nervous system involvement in systemic connective tissue diseases. This complication should not be missed since it seems to respond well to corticosteroids and/or to plasmapheresis if diagnosed in time.
\end{abstract}

\section{Introduction}

Essential or primary mixed cryoglobulinaemia usually presents as polyarthralgia and purpura complicated by liver and kidney disease. Neurological manifestations are only rarely described. The following patient suffered from essential mixed cryoglobulinaemia with involvement of the central nervous system (CNS).

\section{Case report}

A 69-year-old widow was admitted because of progressive weakness and confusion which started a few weeks earlier. The patient was hospitalized in 1978 suffering from Coombs' positive haemolytic anaemia, polyarthralgia and purpura. Cryoglobulins were elevated. These findings were attributed to an unidentified connective tissue disease, since malignant and infectious diseases were ruled out. Corticosteroids were administered with gradual regression of the anaemia and improvement of the patient's general condition. In September 1980 corticosteroids were discontinued. The patient felt well for another month but in October her family noticed a progres- sive mental deterioration, with confusion, partia amnesia, depression and difficulties in speaking. However, the patient herself was complaining only of severe fatigue.

On admission she appeared to be psychotic with loss of memory. The temperature was not elevated, blood pressure $200 / 115 \mathrm{~mm} \mathrm{Hg}$, pulse 60 beats/min regular, the thyroid was mildly and diffusely enlarged. Examination of the lungs, heart, abdomen and limbs was unrevealing.

Laboratory tests: ESR (Westergren) $75 \mathrm{~mm} / \mathrm{h}$, WBC $5.7 \times 10^{9} / 1$ with normal differential count, $\mathrm{Hb}$ $7 \cdot 8 \mathrm{~g} / \mathrm{dl}$, platelets $100 \times 10^{9} / 1$, reticulocytes $1 \cdot 2 \%$, blood urea $13.9 \mathrm{mmol} / \mathrm{l}$, creatinine $203 \mu \mathrm{mol} / \mathrm{l}$, alkaline phosphatase 350 i.u./l $(\mathrm{N}<80$ i.u./l), total protein $59 \mathrm{~g} / \mathrm{l}$, albumin $34 \mathrm{~g} / \mathrm{l}$, globulins $25 \mathrm{~g} / \mathrm{l}$, IgG $5.5 \mathrm{~g} / \mathrm{l}$, IgA $0.77 \mathrm{~g} / \mathrm{l}, \operatorname{IgM} 3.5 \mathrm{~g} / \mathrm{l}$, cryoglobulins were found to consist of both IgM and IgG (mixed cryoglobulins), total haemolytic complement $0, \mathrm{C}_{3} 34 \%, \mathrm{C}_{4} 0$, latex fixation 1:1240, antinuclear factor, Coombs' test and Australia antigen were repeatedly negative, prothrombin time (PT) $11.5 \mathrm{~s}(100 \%)$, partial thromboplastin time (PTT) 27s. The urine contained $11.2 \mathrm{~g} / \mathrm{dl}$ protein with few erythrocytes in the sediment.

The cerebrospinal fluid was clear, the protein $0.45 \mathrm{~g} / \mathrm{l}$, with no cells in the sediment. Bone marrow demonstrated a hypoplastic erythroid line. The electroencephalogram (EEG) revealed a diffuse and nonspecific pattern with interference of the background from theta and delta waves. Isotope brain scan and computed tomography of the brain were normal. Study of the thyroid gland showed a multi-nodular gland with euthyroid activity.

The combination of polyarthralgia, purpura, renal and hepatic involvement with mixed cryoglobulins and a high titre of rheumatoid factor led to the presumptive diagnosis of essential (primary) mixed cryoglobulinaemia. The central nervous system involvement was attributed to the same disease. Since the patient had responded to corticosteroids in the 
past, and deteriorated following steroid withdrawal, these were readministered in a dose of $100 \mathrm{mg}$ flucortolone per day.

During the treatment the signs of organic psychosis subsided and a repeated EEG was normal. Plasmapheresis and cytotoxic drugs were considered but not given in view of the good response to corticosteroids, which were gradually tapered to $60 \mathrm{mg} /$ day. On the 5 th week of hospitalization, acute and transient rectal bleeding appeared, but despite endoscopy, rectoscopy and abdominal angiography, the bleeding site could not be identified. A week later shaking chills, fever and signs of deep phlebothrombosis in the left leg were evident, the patient's condition deteriorated rapidly and she died on the following day. Laboratory tests taken before her death revealed signs of disseminated intravascular clotting and blood cultures yielded Pseudomonas aeruginosa.

Post-mortem examination was performed. The immediate cause of death was sepsis and pulmonary oedema. Vasculitis or neoplasms were not found. Heavy lymphocytic infiltration was seen in the kidney, pancreas, liver, thyroid and parathyroid. Small encephalomalacic cysts were found in the brain.

\section{Discussion}

Mixed cryoglobulinaemia often accompanies diseases, such as connective tissue diseases, infections, neoplasms, and plasma cell dyscrasias. These conditions were excluded in view of the clinical presentation, the laboratory findings and the postmortem examination. The hallmark of primary mixed cryoglobulinaemia is the presence of serum cryoprotein which consists of polyclonal or occasionally monoclonal IgM with rheumatoid factor activity complexed to polyclonal IgG.

Primary essential mixed cryoglobulinaemia occurs predominantly in females. This distinctive clinical syndrome presents as cutaneous vasculitis and arthralgia. Other known manifestations include Sjögren's syndrome, peripheral neuropathy and hepatomegaly. Glomerulonephritis eventually develops in $20 \%$ of the cases and is the major cause of death (Levo et al., 1977; Melzer and Franklin, 1966; Brouet et al., 1974). The prominent laboratory findings are hypocomplementaemia and large amounts of cryoprecipitable proteins, containing a mixture of IgM and IgG. Fibrinoid necrosis is sometimes seen in the dermal vessels, and can occur in association with mesenteric thrombosis, peripheral neuropathy or nephritis. The usual histological finding is either a typical leucocytoclastic vasculitis or lymphocytic infiltration of the vessels (Weisman and Zvaifler, 1980; Tarantino et al., 1981) as was shown in our patient. Immune complexes, with or without complement, sometimes bind only to normal blood lymphocytes; in such a case, no evidence of immune complexes may be found elsewhere (Kammer and Schor, 1978).

Recently it has been found that many of these patients have hepatitis B surface antigen in both serum and isolated immune complexes (Lopez et al., 1980), and retrospectively this could also be a manifestation of the disease. No effective drug therapy is known, but plasmapheresis had been used successfully to control exacerbations (Berkman and Orlin, 1980; Gettner, Kohn and Franklin, 1980). Cyclophosphamide and chlorambucil were tried as well (Berkman et al., 1980; Mathison et al., 1971).

Peripheral neuropathy occurs in mixed cryoglobulinaemia but central nervous system involvement is rarely mentioned (Brouet et al., 1974; Wiesman and Zvaifler, 1980; Kammer and Schor, 1978; Berkman and Orlin, 1980; Gorevic et al., 1980). In Brouet's series of 86 patients with cryoglobulinaemia, one patient had transient blindness and another had a transient hemiparesis (Brouet et al., 1974). Berkman and Orlin (1980) recommended the use of plasmaphaeresis and partial serum exchange in the management of cryoglobulinaemia. They mentioned briefly two patients with mixed cryoglobulinaemia and transient hemiparesis, which was attributed to the disease. Our patient had definite CNS involvemen with psychosis and abnormal EEG findings which improved during corticosteroid treatment, buts unfortunately she died as a result of a pseudomonaș sepsis.

In view of our experience and the few descriptions in the literature, it seems justified to include mixed cryoglobulinaemia in the differential diagnosis of connective tissue diseases which involve the CNS. This diagnosis should not be missed since some of the patients might benefit from corticosteroid therapy or plasmapheresis.

\section{References}

Berkman, E.M. \& ORLIN, J.B. (1980) Use of plasmapheresis and partial plasma exchange in the management of patients with cryoglobulinemia. Transfusion, 20, 171.

Brouet, J.C., Clauvel, J.P., Danon, F., Klein, M. \& SeligmanN, M. (1974) Biologic and clinical significance of cryoglobulins. A report of 86 cases. American Journal of Medicine, 57, 775.

Gettner, D., Kohn, R. \& Franklin, E.C. (1980) Effect of vigorous therapy on 5 patients with mixed cryoglobulinemia with renal and neurological involvement. Arthritis and Rheumatism, 23, 677.

Gorevic, P.D., Kassab, H.J., Levo, Y., Kohn, R., Melzer, M., Prose, P. \& Franklin, E.C. (1980) Mixed cryoglobulinemia: clinical aspects and long term follow up of 40 patients. American Journal of Medicine, 69, 287.

KAMMER, G.M. \& SCHOR, P. (1978) Binding of circulating immune complexes to human peripheral blood lymphocytes: effect of complement. Clinical Immunology and Immunopathology, 10, 202.

Levo, Y., Gorevic, P.D., Kassab, H.J., ZuCKer-Franklin, D. \& Franklin, E.C. (1977) Association between hepa- 
titis B virus and essential mixed cryoglobulinemia. New England Journal of Medicine, 296, 1501.

Lopez, L.R., Schocket, R.E., Stanford, R.E., Claman, H.N. \& KOHLER, P.F. (1980) Gastrointestinal involvement in leucocytoclastic vasculitis and polyarthritis nodosa. Journal of Rheumatology, 7, 677.

Mathison, D.A., Condemi, J.J., Leddy, J.P., Callerame, M.I., Pauner, B.J. \& Vaughan, J.H. (1971) Purpura arthralgia and IgG-IgM cryoglobulinemia with rheumatoid factor activity. Response to cyclophosphamide. Annals of Internal Medicine, 74, 383.

Merzer, M. \& Franklin, E.C. (1966) Cryoglobulinemia-a study of twenty-nine patients. I. IgG and IgM cryoglobulin and factors affecting cryoprecipitability. American Journal of Medicine, 40, 828.

Tarantino, A., De Vecchi, A., Montagnino, G., Imbasciati, E., Mihatsch, M.J., Zollinger, H.U., Barbiano Di Belgiojoso, G., Busnach, G. \& Ponticflli, C. (1981) Renal disease in essential mixed cryoglobulinemia-long term follow up of 44 patients. Quarterly Journal of Medicine, 50, 197.

Weisman, M.H. \& ZVAIfleR, N.J. (1980) Vasculitis in connective tissue diseases. Clinics in Rheumatic Diseases, 6, 357. 